\title{
Fluoride Excess Removal from Brackish Drinking Water in Senegal by Using KSF and K10 Montmorillonite Clays
}

\author{
Saïdou N. Diop" ${ }^{*}$, Mohamad M. Dieme¹, Mouhamadou A. Diallo², Courfia K. Diawara1 \\ ${ }^{1}$ UFR Sciences \& Technologies, Université Assane Seck de Ziguinchor, Ziguinchor, Senegal \\ ${ }^{2}$ Faculté des Sciences Technique, Université Cheikh Anta Diop, Dakar, Senegal \\ Email: *sndiop@univ-zig.sn
}

How to cite this paper: Diop, S.N., Dieme, M.M., Diallo, M.A. and Diawara, C.K. (2022) Fluoride Excess Removal from Brackish Drinking Water in Senegal by Using KSF and K10 Montmorillonite Clays. Journal of Water Resource and Protection, 14, 21-34.

https://doi.org/10.4236/jwarp.2022.141002

Received: November 23, 2021

Accepted: January 16, 2022

Published: January 19, 2022

Copyright $\odot 2022$ by author(s) and Scientific Research Publishing Inc. This work is licensed under the Creative Commons Attribution International License (CC BY 4.0).

http://creativecommons.org/licenses/by/4.0/

\begin{abstract}
Fluoride excess in drinking water is noticed in many countries around the world and particularly in Senegal where, in addition to fluoride excess, high levels of salinity are also encountered. In order to reduce fluoride excess in drinking water in the groundnut basin of Senegal, two types of clays namely montmorillonite $\mathrm{KSF}$ and montmorillonite $\mathrm{K} 10$ as well were used as adsorbent materials. The results show that the $\mathrm{pH}$ which was initially alkaline becomes acidic varying from 2.80 to 6.80 . The pseudo first-order kinetic model fit well with the adsorption experiments for KSF montmorillonite $\left(r^{2}=0.96\right)$, while for K10 clay the same model describe the experiments with slight differences $\left(r^{2}=0.90\right)$. The KSF clay has a better fluoride adsorption capacity compared to that obtained with K10 clay due to the presence of a great level of calcium oxide in the montmorilonite KSF clay.
\end{abstract}

\section{Keywords}

Fluoride, Brackish Water, Montmorillonite KSF, Montmorillonite K10

\section{Introduction}

The contamination of groundwater by fluoride ions has been recognized as one of the health problems affecting several countries around the world. Senegal is not spared by excess of fluoride ions in groundwater, especially in the groundnut basin area [1] [2].

Fluoride is an essential element in the human body as long as its concentration in drinking water does not exceed a certain limit [3]. As an example in relation to this limit, the World Health Organization (WHO) fixes the concentration 
of $1.5 \mathrm{mg} \cdot \mathrm{L}^{-1}$ as the admissible dose of fluoride in water intended for human consumption [4]. When the concentration of fluoride ions in drinking water is above this recommended limit, its consumption can cause dental and/or bone fluorosis and even reach certain organs such as the liver, thyroid... [5].

The World Health Organization has thus made a classification on pollutants in drinking water and fluorine is part of this classification along with arsenic, nitrate, etc. More than 200 million people around the world are affected by the excessive concentration of fluoride in their drinking water [6].

Based on this observation, several researchers have focused on the elimination of all pollutants in drinking water that can cause real health problems for populations. With regard to the specific case of fluoride, subject of this study, it's a trace element considered as necessary and beneficial for the human body at doses that comply with WHO recommendations. Thus, several technologies are developed and used for the elimination of fluoride excess in drinking water [7] [8]. Among these technologies, membrane systems are widely used and the effectiveness of membranes on the removal of fluoride excess from brackish water no longer needs to be demonstrated. However, membrane technology remains expensive, which limits its use especially in developing countries. Indeed, these reasons make that the technique of separation by adsorption is more and more expanding. The adsorption technique has the advantage over membrane technologies on investment costs. In fact, several agricultural residues can be used as precursors to produce activated carbon. This adsorbent is one of the most widely used and most effective adsorbents in water treatment [9] [10]. In addition, adsorption on clay, on activated alumina has also been developed by several authors since a very long time [6] [11].

The main objective of this study is to test the effectiveness of the removal of fluoride excess in drinking water from the groundnut basin of Senegal by adsorption on two types of clays called montmorillonite KSF and K10. Then, a modeling will be carried out by using kinetics and isotherms of adsorption. For the treatment with the montmorillonites KSF and K10, experiments of adsorption by stirring were carried out by varying both the adsorption dose as well as the duration of stirring.

\section{Hydrogeology of Fluorinated Water}

From a geological point of view, water contaminated with fluoride ions can be found in the three main types of terrain: sedimentary basins, crystalline basement areas and volcanic regions. In the first case, the origin of fluoride comes from the fact that, except for evaporites, fluoride is the most abundant halogen of sedimentary rocks. In the second case, the best known and most documented region is the East African Rift, where levels of up to $180 \mathrm{mg} \cdot \mathrm{L}^{-1}$ have been observed in lakes in Kenya [12]. Fluoride then comes either from the leaching of alkaline magmatic rocks with minerals such as apatite, topaz or fluorite or from volcanic activity itself which generates fluorinated gas inputs such as HF [13]. 
Finally, examples of groundwater largely exceeding the fluoride content recommended by the WHO guidelines $\left(<1.5 \mathrm{mg} \cdot \mathrm{L}^{-1}\right)$ and originating from granite aquifers have been located in India, Thailand, China, South Africa and in the eastern part of Senegal.

A mapping of the fluoride content in groundwater in Senegal (Figure 1) shows that the areas exceeding the limits recommended by the WHO guidelines are those located in the center-west (regions of Fatick, Diourbel, Kaolack, Thies)

Indeed, it is the water from wells capturing the Eocene that is the most highly fluorinated. In the terminal continental and quaternary aquifers, the waters are generally less mineralized in fluoride. The ionic composition of groundwater tables is naturally variable depending on the geology of the aquifers. We also observe an increase in mineralization with the depth of the aquifer, which justifies the high fluoride contents noted in the Maastrichtian aquifer [14].

\section{Fluoride and Health}

The consumption of excessively fluorinated water can have negative effects on the health of populations that are exposed to these waters. The fluoride content in drinking water must therefore meet very specific standards.

\subsection{Standards and Recommendations}

Fluoride is a necessary trace element that is beneficial to the human body at low concentrations, but toxic at higher doses. In fact, from the fluoride content of 0.5 $\mathrm{mg} \cdot \mathrm{L}^{-1}$, water plays a prophylactic role, but the risk of fluorosis begins and becomes strong above $1.5 \mathrm{mg} \cdot \mathrm{L}^{-1}[14]$.

A relationship between the concentration of fluoride in water and the risk of fluorosis has been made, thus between 0.5 and $1.5 \mathrm{mg} \cdot \mathrm{L}^{-1}$, good dental health is promoted; between 1.5 and $4 \mathrm{mg} \cdot \mathrm{L}^{-1}$, there is a risk of dental fluorosis; between 4

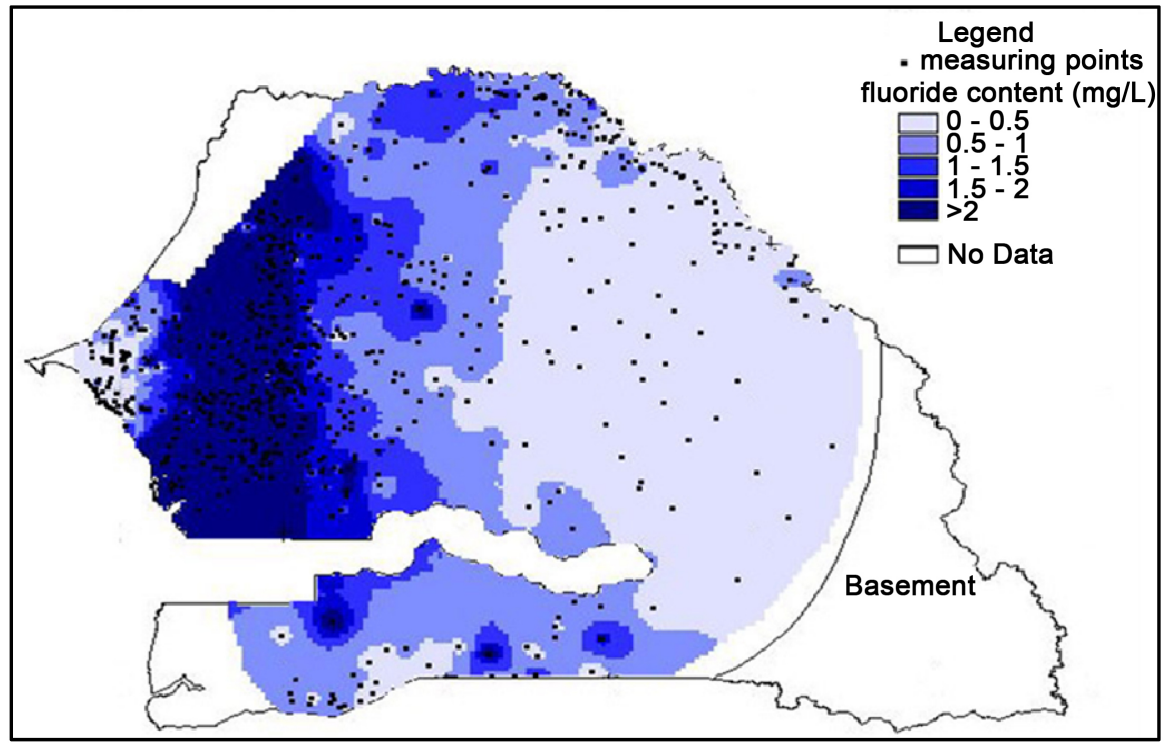

Figure 1. Mapping of fluorinated water in Senegal. 
and $10 \mathrm{mg} \cdot \mathrm{L}^{-1}$, fluorosis affects teeth and/or bones; and above $10 \mathrm{mg} \cdot \mathrm{L}^{-1}$ an advanced stage of fluorosis (crippling fluorosis) is reached [13] [14].

In Senegal, as in many other countries around the world, studies show that from $2 \mathrm{mg} \cdot \mathrm{L}^{-1}$, all children are affected and that $60 \%$ of them have severe fluorosis for levels around $4 \mathrm{mg} \cdot \mathrm{L}^{-1}$ [14]. Thus, an optimal fluoride content in drinking water between 0.5 and $0.65 \mathrm{mg} \cdot \mathrm{L}^{-1}$ has been found in an endemic region of southern India [15].

Fluoride absorption in the body occurs by diffusion throughout the digestive tract, the speed being a function of the solubility of fluorides and gastric acidity. About $99 \%$ of the total fluoride in the body is located in calcified tissues (i.e., bones and teeth) where it substitutes for the hydroxyl ions $\left(\mathrm{OH}^{-}\right)$in hydroxyapatite to form fluorapatite. In bones, which contain $96 \%$ of the body's burden, fluoride causes an increase of apatite crystals size and their solubility decrease [16].

\subsection{Dental Fluorosis}

The immediate consequences of regular consumption of water with excessive fluoride content are dental fluorosis and skeletal fluorosis [17] [18]. Dental fluorosis has been described in many countries around the world: in Morocco, Kenya, Tanzania, Senegal, India, Europe, the United States particularly in countries where populations consume water whose fluoride content is relatively high [15] [17]. Dental fluorosis is defined, according to Cutress and Suckling, as "hyper-mineralization of dental enamel induced by fluoride near the developing tooth during the secretory and/or maturation phases of amelogenesis".

The enamel can be speckled in brown or white with streaks [19], bands or even have the characteristic appearance of "chalky" teeth. In the mildest forms, only the surface layer of the enamel is affected and diffuse white lines appear on the tooth. As the severity increases, the deeper layers are affected and the porosity becomes significant, which gives the teeth a chalky white appearance [20] [21]. One of the most recognizable symptoms is tooth stains (Figure 2) [22]. The

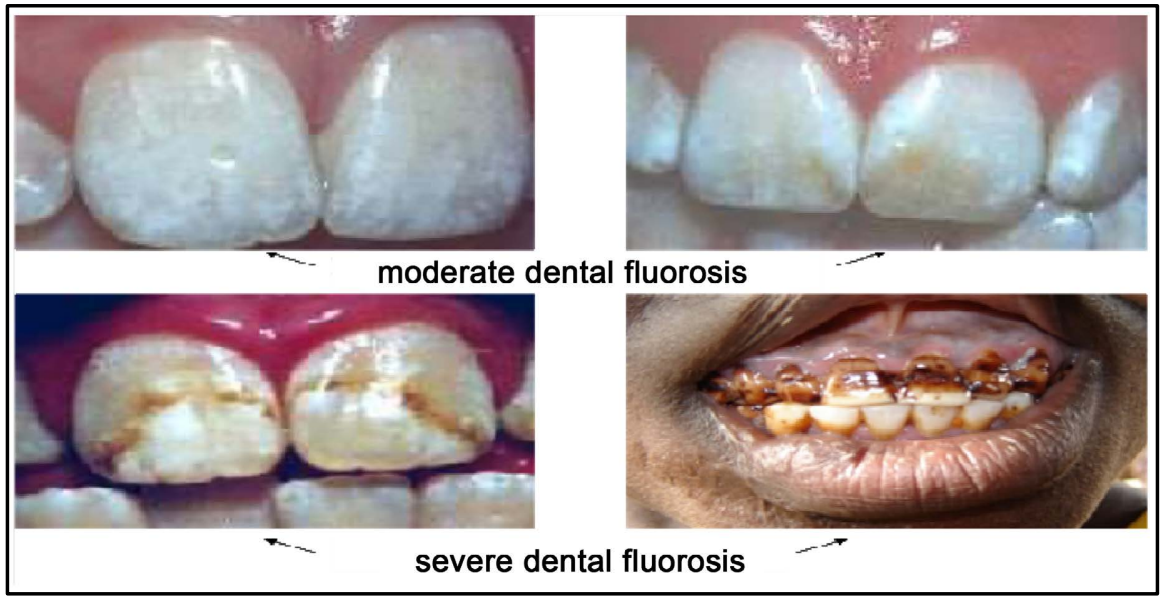

Figure 2. Cases of dental fluorosis. 
prevalence, metabolism and risks of developing dental fluorosis have been developed by some authors [23].

In general, mild forms of dental fluorosis do not affect dental function and are considered esthetic rather than health problems.

\subsection{Skeletal Fluorosis}

Bone fluorosis is defined as skeletal damage associated with chronic fluoride poisoning. Skeletal fluorosis manifests itself after a number of years (at least 10 years) at water concentrations above $4 \mathrm{mg} \cdot \mathrm{L}^{-1}$ of fluoride.Prolonged and intense exposure of around 10 to $40 \mathrm{mg} /$ day can be the cause of osteopathic manifestations which can be observed in the skeleton [16]. Bone pain, joint stiffness are the signs of onset of fluoride poisoning. Bone fluorosis, precisely in its first phase, is a difficult disease to diagnose and can be quickly confused with various forms of arthritis including osteoarthritis and rheumatoid arthritis. At a more advanced stage, the increase in bone mass and deformities can lead to joint and spinal dysfunctions, muscle atrophy, compression-type neurological abnormalities. In its advanced stages, skeletal fluorosis can resemble to bone and joint diseases such as: osteosclerosis, renal osteodystrophy, osteoporosis and secondary hyperthyroid, etc.

In the case of severe fluorosis, some sufferers may experience deformities in the bones (Figure 3) [22]. A relationship between osteosclerosis and skeletal fluorosis has been demonstrated in an endemic region in southern Turkey [24].

\section{Materials and Methods}

The experiments carried out in the laboratory consisted of studying the efficiency of the removal of fluoride by varying the mass of adsorbent and the stirring time in order to determine the optimum mass and stirring time.

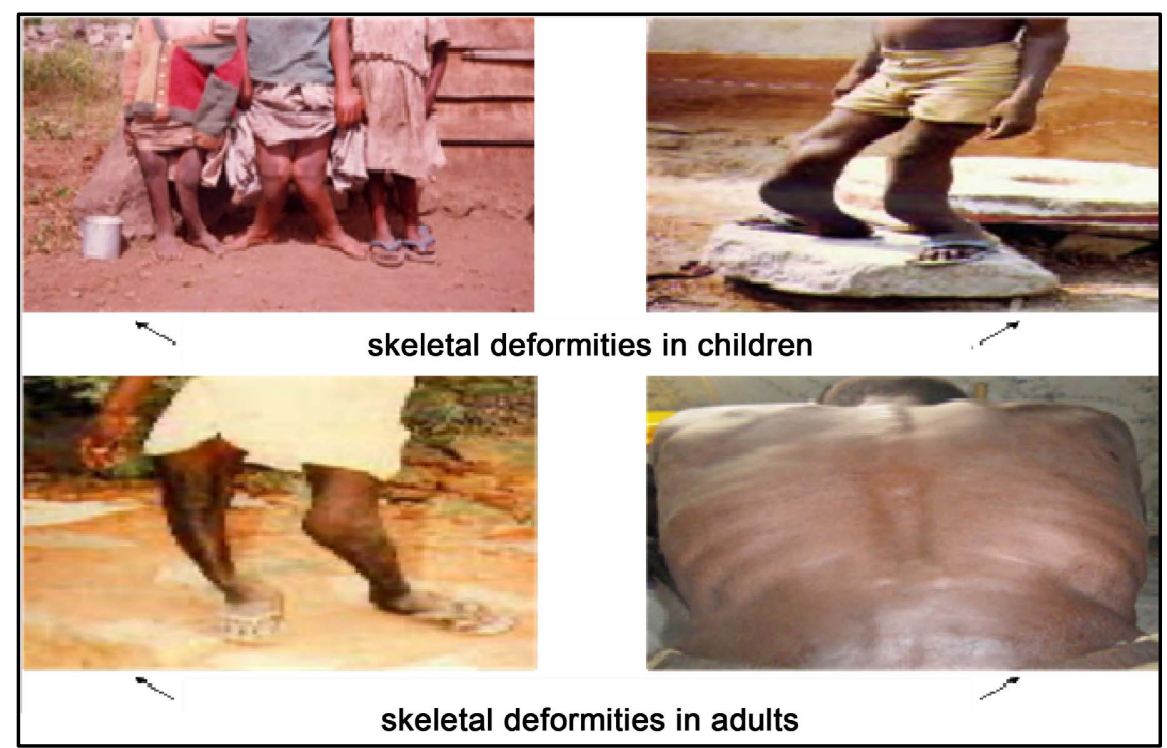

Figure 3. Cases of bone fluorosis. 


\subsection{Clays Used}

Montmorillonite KSF (KSF) and montmorillonite K10 (K10) clays were used as adsorbents in this study. The characterization data provided by ALDRICH are grouped together in Table 1.

\subsection{Fluoride Adsorption on Clay}

For the adsorption experiments, $1 \mathrm{~g}$ of montmorillonite KSF and a volume of $150 \mathrm{~mL}$ of the fluorinated water solution are introduced into a beaker with a capacity of $250 \mathrm{~mL}$. In a first step, a synthetic solution of $4.50 \mathrm{mg} \cdot \mathrm{L}^{-1}$ was prepared with $\mathrm{NaF}$ in order to obtain a fluoride concentration close to that of the water encountered on site. The solution in the beaker is then stirred for 15, 30, 60, 120 and 240 minutes in order to study the maximum adsorption time. At the end of the stirring time, the solution is left to stand for 5 minutes to settle and then filtered using filters with a diameter of $0.45 \mu \mathrm{m}$. In a second step, real water solutions taken from urban and rural areas in the regions of Diourbel, Fatick and Kaolack in Senegal were tested. Stirring is carried out for the time for which the adsorption was maximum for synthetic solutions. The same experimental protocol was used with montmorillonite K-10 clay.

All fluorine concentration measurements were carried out with the "MULTIDIRECT" photometer. The equilibrium adsorption capacities $\left(q_{e}\right)$ were determined with Equation (1) below.

$$
q_{e}\left(\mathrm{mg} \cdot \mathrm{g}^{-1}\right)=\frac{\left(C_{0}-C_{e}\right) V}{m}
$$

where: $C_{0}\left(\mathrm{mg} \cdot \mathrm{L}^{-1}\right)$ and $C_{e}\left(\mathrm{mg} \cdot \mathrm{L}^{-1}\right)$ are the initial and equilibrium concentrations, respectively; $m(\mathrm{~g})$ and $V(\mathrm{~L})$ are the adsorbent amount and volume in the reactor.

The kinetics are carried out with continuous stirring for 240 minutes using a magnetic stirrer at $150 \mathrm{rpm}$. Measurements of the residual concentration until the saturation of the adsorbent material is observed. The equilibrium time between the adsorbent and the solution is determined by plotting the curve of the residual fluoride concentration versus time. Thus, the pseudo first and second order models proposed by Mckay were used to describe this kinetics [25] [26]. The first order Equation (2) and the second order Equation (3) used are as follows:

$$
\frac{\mathrm{d} q_{t}}{\mathrm{~d} t}=k_{1}\left(q_{e}-q_{t}\right)
$$

Table 1. Chemical composition of KSF and K10 clays.

\begin{tabular}{cccccccccc}
\hline & $\mathrm{SiO}_{2}$ & $\mathrm{Al}_{2} \mathrm{O}_{3}$ & $\mathrm{CaO}$ & $\mathrm{MgO}$ & $\mathrm{Na}_{2} \mathrm{O}$ & $\mathrm{K}_{2} \mathrm{O}$ & $\mathrm{Fe}_{2} \mathrm{O}_{3}$ & $\mathrm{H}_{2} \mathrm{SO}_{4}$ & $\mathrm{~S}_{\mathrm{BET}}$ \\
\hline $\mathrm{KSF}$ & 53.2 & 18.8 & 2.9 & 2.8 & - & - & 5.1 & 6 & - \\
$\mathrm{K} 10$ & 73 & 14 & 0.2 & 1.1 & 0.6 & 1.9 & 2.7 & - & 250 \\
\hline
\end{tabular}




$$
\frac{\mathrm{d} q_{t}}{\mathrm{~d} t}=k_{2}\left(q_{e}-q_{t}\right)^{2}
$$

where: $q_{e}$ and $q_{t}$ the adsorption capacities at equilibrium and at time $t ; k_{1}$ and $k_{2}$ the first and second order constants.

Adsorption isotherm models will also be applied to the results obtained in order to determine the maximum adsorption capacity of the two types of clays used. The models of Langmuir (Equation (4)) [27] and Freundlich (Equation (5)) [28] will be used to determine the maximum adsorption capacities.

$$
\begin{gathered}
q_{e}\left(\mathrm{mg} \cdot \mathrm{g}^{-1}\right)=\frac{q_{\mathrm{m}} b_{L} C_{e}}{1+b_{L} C_{e}} \\
q_{e}\left(\mathrm{mg} \cdot \mathrm{g}^{-1}\right)=K_{f} C_{e}^{1 / n}
\end{gathered}
$$

where: $q_{m}\left(\mathrm{mg} \cdot \mathrm{g}^{-1}\right)$ is maximum adsorption capacity corresponding to complete monolayer coverage; $b_{L}\left(\mathrm{~L} \cdot \mathrm{mg}^{-1}\right)$ is the equilibrium constant related to the energy of sorption.

$K_{f}\left[\left(\mathrm{mg} \cdot \mathrm{g}^{-1}\right) /\left(\mathrm{mg} \cdot \mathrm{L}^{-1}\right)^{1 / n}\right]$ and $n$ are the Freundlich isotherm constants related to adsorption capacities and the degree of favorability of adsorption, respectively.

Several studies carried out in the literature will be used for a comparative study which will help us in the interpretation of our results in the third part of this paper which will be devoted to the results and their discussions.

\subsection{Adsorption Kinetics}

\subsubsection{Pseudo First Order Kinetic Model}

The pseudo first order kinetic adsorption model is based on Equation (2) and on the amount of adsorbate attached to the surface of the adsorbent. By integrating Equation (2) for the boundary conditions from $t=0$ to $t=t$ and from $q_{e}$ to $q_{t}=q_{t}$ the below equation is obtained (Equation (6)):

$$
\log \left(q_{e}-q_{t}\right)=\log q_{e}-\frac{k_{1}}{2.303} t
$$

The parameters $q_{e}$ and $k_{1}$ will be determined by linear regression by plotting $\log \left(q_{e}-q_{t}\right)$ versus $t$.

\subsubsection{Pseudo Second Order Kinetic Model}

The pseudo second order kinetic adsorption model corresponds to Equation (3). By integrating Equation (3) for the boundary conditions used to obtain equation 6. With these conditions the below equation (Equation (7)) is obtained.

$$
\frac{t}{q_{t}}=\frac{1}{k_{2} q_{e}^{2}}+\frac{1}{q_{e}} t
$$

The parameters $q_{e}$ and $k_{2}$ are obtained experimentally by plotting $\frac{t}{q_{t}}$ versus $t$. 


\section{Results and Discussion}

\section{1. pH Variation}

The initial $\mathrm{pH}$ of an aqueous solution is a very important parameter, which can influence the adsorption process by controlling the surface charge of the adsorbent [29]. The $\mathrm{pH}$ values measured in the water samples before the kinetic study reveal that the variation ranges between 7.67 and 8.70; which is characteristic of alkaline $\mathrm{pH}$ and these $\mathrm{pH}$ values are within the range recommended by WHO [30]. At the end of the kinetic study, a systematic measurement of the final $\mathrm{pH}$ was carried out. These measurements showed a variation in the values from alkaline $\mathrm{pH}$ to very acidic $\mathrm{pH}$. The values obtained vary between 2.80 and 6.80 . Thus, the concentration of fluoride ions is reduced within the range of WHO recommendation. In the literature, the best adsorption capacities where the efficiency of adsorbent materials (activated carbon, clays, etc.) are obtained correspond to somewhat acidic $\mathrm{pH}$ ranges, and rarely exceed $\mathrm{pH}$ 7. A decrease in the percentage of fluoride ion removal can be observed towards $\mathrm{pH}$ values of 8 to 9 according to certain authors [31] [32]. Acidic $\mathrm{pH}$ also remains a problem to be resolved, because with these acidic $\mathrm{pH}$ values, the water cannot be consumed directly without modification of the $\mathrm{pH}$ in order to have a $\mathrm{pH}$ range for water intended for human consumption.

\subsection{Fluoride Adsorption Kinetics with KSF and K10 Clays}

As indicated in the material and methods section, adsorption kinetics are carried out with KSF and K10 clays with different samples to find out after how long the equilibrium will be reached with each of these two clays. The same amount of adsorbent (KSF and K10 clay) is used for each study, and under the same working conditions. The shape of the curves obtained during the kinetic study is shown in Figure 4.

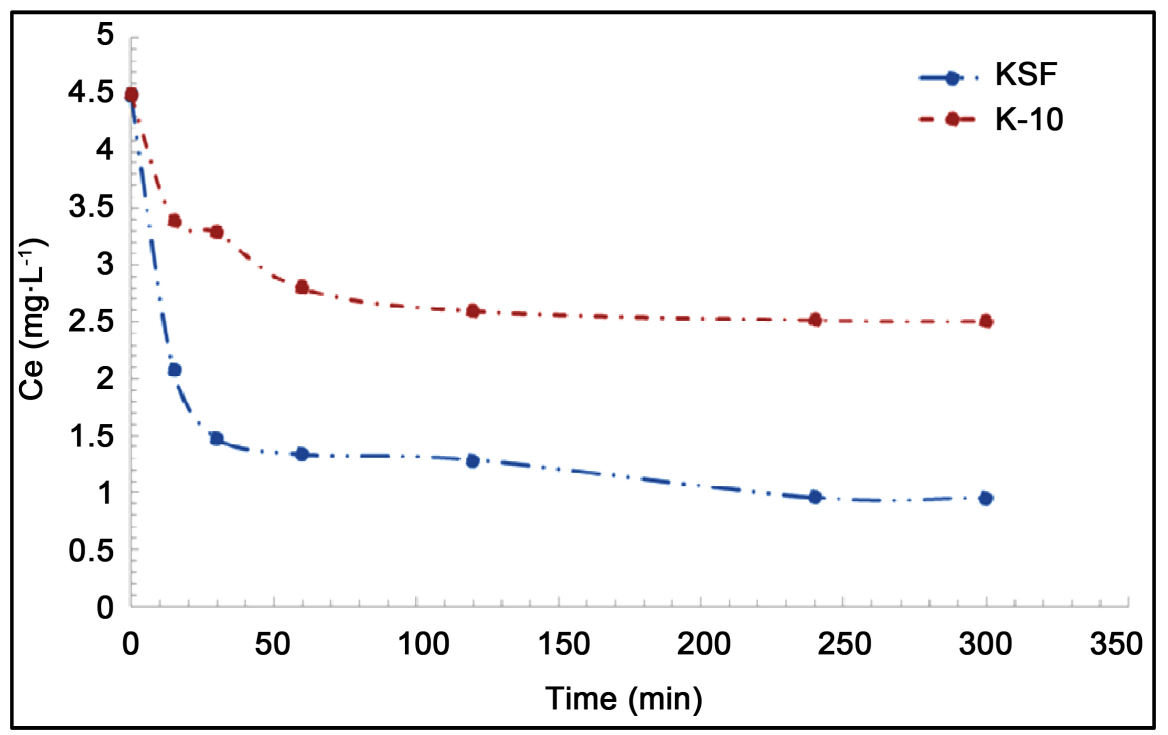

Figure 4. Fluoride ions adsorption kinetics with KSF and K10 clays. 
From these two kinetics curves (Figure 4), a similarity in the equilibrium time of the two clays is practically observed. However, the difference is especially noted in the amount of fluoride adsorbed by each of these two clays. Adsorption equilibrium is obtained after 4 hours of kinetics. The experimental adsorption capacities obtained with the KSF and K10 adsorbents after 4 hours are 0.532 $\mathrm{mg} \cdot \mathrm{g}^{-1}$ and $0.298 \mathrm{mg} \cdot \mathrm{g}^{-1}$ respectively. It is clear that KSF clay has a better adsorption capacity compared to that obtained with K10 clay.

In fact, the chemical composition of these clays (Table 1) reveals a significant presence of calcium oxide in KSF clay with a concentration which is $2.9 \mathrm{mg} \cdot \mathrm{L}^{-1}$ whereas it is $0.2 \mathrm{mg} \cdot \mathrm{L}^{-1}$ for $\mathrm{K} 10$ clay. A coordination reaction has been reported in the literature when a solution containing fluoride ions is brought into contact with an adsorbent surface having a certain concentration of calcium oxide. In an adsorbent material, the higher its mass concentration of calcium, the better its adsorption capacity for fluoride ions [33]. Therefore, the real difference in adsorption capacity between KSF clay and K10 one is due to the greater presence of calcium oxide in KSF. With an initial concentration of $4.5 \mathrm{mg} \cdot \mathrm{L}^{-1}$, after $30 \mathrm{~min}$ of adsorption, the KSF clay has adsorbed a significant amount of fluoride ions, thus obtaining an equilibrium residual concentration below the limit recommended by WHO for water intended for human consumption $\left(1.5 \mathrm{mg} \cdot \mathrm{L}^{-1}\right)$.

Table 2 groups the experimental adsorption capacities $\left(q_{e, \text { exp }}\right)$ and those calculated $\left(q_{e, \text { cal }}\right)$ by linear regression using the linearized equations of the pseudo first order (6) and pseudo second order (7).

Pseudo first order and pseudo second order adsorption kinetics were used to describe the adsorption kinetics obtained with KSF clay and the adsorption kinetics obtained with K10 clay.

Regarding the pseudo first order kinetic adsorption model, it allows a better description of the kinetics obtained with KSF clay with $r^{2}=0.96$ compared to the application of the same model on the kinetics of K10 clay $\left(r^{2}=0.90\right)$. Indeed, this is why the experimental adsorption capacity obtained with KSF $\left(q_{e, \text { exp }}=0.532 \mathrm{mg} \cdot \mathrm{g}^{-1}\right)$ is close to that calculated with the pseudo first order model $\left(q_{e, c a l}=0.569 \mathrm{mg} \cdot \mathrm{g}^{-1}\right)$. However, with $\mathrm{K} 10$ clay, the experimental adsorption capacity obtained is significantly different from that which was calculated. This means that the pseudo first order kinetic model does not allow a better description of the experiment with K10 clay. In the literature, it has been shown that the first order kinetic adsorption model is often valid in the time interval between 20 to 30 minutes, otherwise the model does not allow a better

Table 2. Parameters of pseudo first and second order kinetics models.

\begin{tabular}{ccccccccc}
\hline & \multicolumn{3}{c}{ Pseudo first order } & \multicolumn{3}{c}{ Pseudo second order } \\
\cline { 2 - 8 } Clays & $q_{e, \text { exp }}\left(\mathrm{mg}^{-1}\right)$ & $q_{e, \text { cal }}\left(\mathrm{mg} \cdot \mathrm{g}^{-1}\right)$ & $\begin{array}{c}K_{1} \\
\left(\mathrm{~min}^{-1}\right)\end{array}$ & $r^{2}$ & $q_{e, \text { exp }}\left(\mathrm{mg} \cdot \mathrm{g}^{-1}\right)$ & $q_{e, \text { cal }}\left(\mathrm{mg}^{\left.-\mathrm{g}^{-1}\right)}\right.$ & $K_{2}$ \\
$\left(\mathrm{~min}^{-1}\right)$ & $r^{2}$ \\
\hline KSF & 0.532 & 0.569 & 0.024 & 0.96 & 0.532 & 0.533 & 4.334 & 0.99 \\
K10 & 0.298 & 0.448 & 0.020 & 0.90 & 0.298 & 0.295 & 7.715 & 0.99 \\
\hline
\end{tabular}


description [34] [35].

By applying the pseudo second order kinetic model, a better description is obtained with the experimental adsorption kinetics for the two clays. The experimental adsorption capacities obtained with KSF and K10 clay are almost identical to those obtained by calculation; Moreover, this is why the correlation coefficients $r_{2}$ obtained are close to unity. We can notice that with this pseudo second order model, the description of the adsorption kinetics is often correct with a correlation coefficient $\mathrm{r}^{2}$ which tends towards unity [3].

\subsection{Adsorption Capacity Determination with Langmuir and Freundlich Models}

A modeling of the adsorption capacity of clays is applied using the Langmuir model and that of Freundlich to the adsorption isotherm of KSF clay, since it has a better adsorption capacity compared to K10 clay. Figure 5 shows the shape of the adsorption capacities versus time.

After modeling, the Freundlich model did not allow a good description of the experiment, it was rather the Langmuir model which gave a closer description with respect to the experiment. Table 3 gathers the characteristic values obtained with the kinetic model of Langmuir.

The results reported in Table 3 show that the maximum adsorption capacity $\left(q_{m}\right)$ obtained with the Langmuir isotherm model is $0.309 \mathrm{mg} \cdot \mathrm{g}^{-1}$ with a correlation coefficient of $r^{2}=0.86$. With this relatively low regression coefficient, the

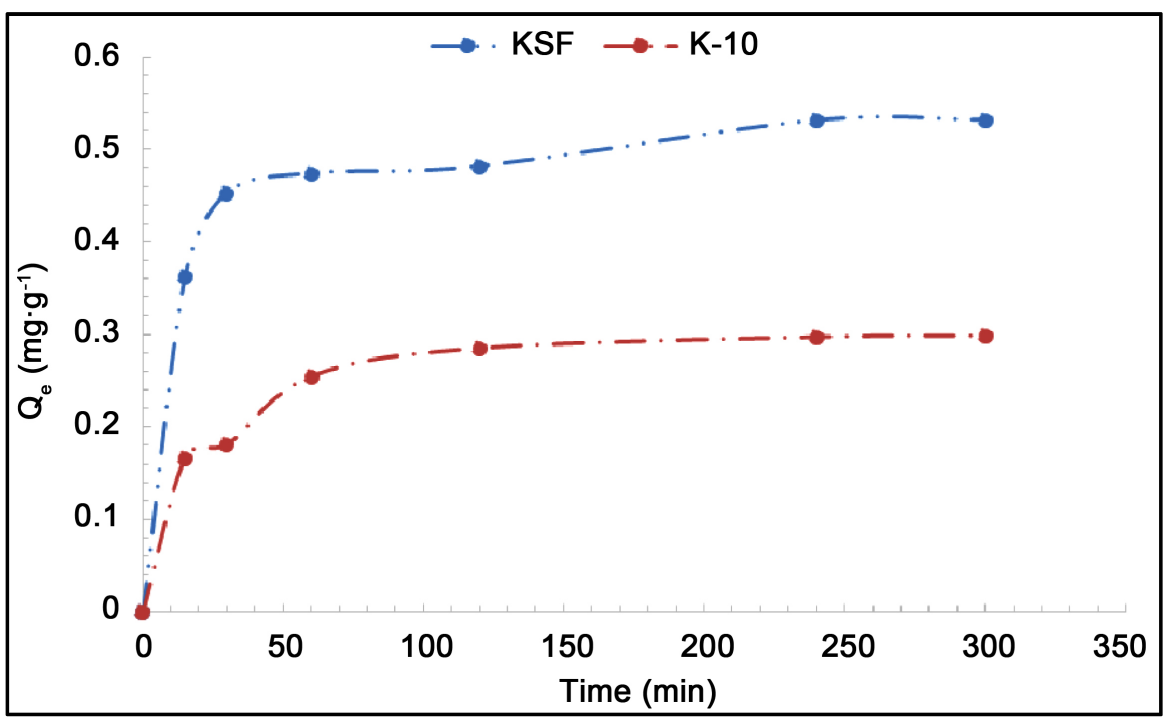

Figure 5. Adsorption capacity of clays versus time.

Table 3. Maximal adsorption capacity obtained with Langmuir model.

\begin{tabular}{ccccc}
\hline \multirow{2}{*}{ Clay } & experience & \multicolumn{3}{c}{ Langmuir model } \\
\cline { 2 - 5 } & $q_{e}\left(\mathrm{mg} \cdot \mathrm{g}^{-1}\right)$ & $q_{m}\left(\mathrm{mg} \cdot \mathrm{g}^{-1}\right)$ & $b_{L}\left(\mathrm{~L} \cdot \mathrm{mg}^{-1}\right)$ & $r^{2}$ \\
\hline \multirow{2}{*}{$\mathrm{KSF}$} & 0.532 & 0.309 & -2.371 & 0.86 \\
\hline
\end{tabular}


value of the maximum adsorption capacity cannot be close to that obtained experimentally $\left(0.532 \mathrm{mg} \cdot \mathrm{g}^{-1}\right)$. Moreover, this is why the value of the coefficient $\mathrm{bL}$, relating to the affinity between the surface of the adsorbent and the adsorbate is negative. Thus, the Freundlich and Langmuir models are not suitable for a better description of the adsorption isotherm.

\section{Conclusions}

In this study, two clays were used for the removal of fluoride ions excess of brackish drinking water from the groundnut basin of Senegal by adsorption. The results of the adsorption tests show that the clay called K10 is less efficient with an adsorption capacity of $0.298 \mathrm{mg} \cdot \mathrm{g}^{-1}$ and an equilibrium concentration still remaining above the WHO guidelines.

On the other hand, with KSF clay an adsorption capacity of $0.532 \mathrm{mg} \cdot \mathrm{g}^{-1}$ is obtained, with an equilibrium concentration of $1.5 \mathrm{mg} \cdot \mathrm{L}^{-1}$ obtained after $25 \mathrm{mi}$ nutes of adsorption kinetics. Thus, the KSF clay can be used for the elimination of fluoride ions excess from brackish drinking water, with an adjustment of the $\mathrm{pH}$, but also a change of adsorbent after 5 hours of contact time.

Pseudo first order and pseudo second order adsorption kinetics were used to describe the adsorption kinetics obtained with KSF clay and the adsorption kinetics obtained with K10 clay. The pseudo first order kinetic adsorption model allows a better description of the kinetics obtained with KSF clay with $r^{2}=0.96$ than with K10 clay ( $\left.r^{2}=0.90\right)$; which proves an experimental adsorption capacity obtained with $\mathrm{KSF}\left(q_{e, \text { exp }}=0.532 \mathrm{mg} \cdot \mathrm{g}^{-1}\right)$ closer to that calculated with the pseudo first order model $\left(q_{e, \text { cal }}=0.569 \mathrm{mg} \cdot \mathrm{g}^{-1}\right)$.

It would be important to dope these clays with cations such as iron capable to fix fluoride ions in order to improve their retention. Mixing the clays in different proportions can be studied to see their impact on the effectiveness of the treatment.

\section{Acknowledgements}

The authors are grateful to the ministry for the scientific research in Senegal within the framework of its "FIRST" program for the financial support.

\section{Conflicts of Interest}

The authors declare no conflicts of interest regarding the publication of this paper.

\section{References}

[1] Diallo, M.A., Diop, S.N., Dieme, M.M. and Diawara, C.K. (2015) Efficiency of Nanofiltration Membrane TFC-SR3 and SelRo MPF-34 for Partial Elimination of Fluoride and Salinity from Drinking Water. Journal of Water Resource and Protection, 7, 457-462. https://doi.org/10.4236/jwarp.2015.77043

[2] Dieme, M.M., Hervy, M., Diop, S.N., Gerente, C., Villot, A., Andres, Y., Diawara, C.K. (2016) Sustainable Conversion of Agriculture and Food Waste into Activated 
Carbons Devoted to Fluoride Removal from Drinking Water in Senegal. International Journal of Chemistry, 8, 8-15. https://doi.org/10.5539/ijc.v8n1p8

[3] He, Y., Zhang, L., An, X., Wan, G., Zhu, W., andLuo, Y. (2019) Enhanced Fluoride Removal from Water by Rare Earth (La and Ce) Modified Alumina: Adsorption Isotherms, Kinetics, Thermodynamics and Mechanism. Science of the Total Environment, 688, 184-198. https://doi.org/10.1016/j.scitotenv.2019.06.175

[4] Fawell, J., Bailey, K., Chilton, J., Dahi, E., Fewtrell, L. and Magara, Y. (2006) Fluoride in Drinking Water. World Health Organization, IWA Publishing, Geneva, Essex. https://doi.org/10.1038/sj.ebd.6400578

[5] C.A. Yeung, (2008) A Systematic Review of the Efficacy and Safety of Fluoridation. Evidence-Based Dentistry, 9 39-43. https://doi.org/10.1016/j.cej.2011.05.028

[6] Bhatnagar, A., Kumar, E. and Sillanpää, M. (2011) Fluoride Removal from Water by Adsorption-A Review. Chemical Engineering Journal, 171, 811-840.

[7] Gupta, V.K. and Ali, I. (2013) Chapter 2. Water Treatment for Inorganic Pollutants by Adsorption Technology. In: Gupta, V.K. and Ali, I. (Author), Environmental Water, Elsevier, Amsterdam, 29-91. https://doi.org/10.1016/B978-0-444-59399-3.00002-7

[8] Onorato, C., Banasiak, L.J. and Schäfer, A.I. (2017) Inorganic Trace Contaminant Removal from Real Brackish Groundwater Using Electrodialysis. Separation and $\mathrm{Pu}$ rification Technology, 187, 426-435. https://doi.org/10.1016/j.seppur.2017.06.016

[9] Dehghani, M.H., Haghighat, G.A., Yetilmezsoy, K., Mckay, G., Heibati, B., Tyagi, I., Agarwal, S. and Gupta, V.K. (2016) Adsorptive Removal of Fluoride from Aqueous Solution Using Single- and Multi-Walled Carbon Nanotubes. Journal of Molecular Liquids, 216, 401-410. https://doi.org/10.1016/j.molliq.2016.01.057

[10] Fito, J., Said, H., Feleke, S. and Worku, A. (2019) Fluoride Removal from Aqueous Solution onto Activated Carbon of Catha edulis through the Adsorption Treatment Technology. Environmental Systems Research, 8, Article No. 25. https://doi.org/10.1186/s40068-019-0153-1

[11] Chaturvedi, A.K., Pathak, K.C. and Singh, V.N. (1988) Fluoride Removal from Water by Adsorption on China Clay. Applied Clay Science, 3, 337-346. https://doi.org/10.1016/0169-1317(88)90024-5

[12] Gaciri, S.J. and Davies, T.C. (1993) The Occurrence and Geochemistry of Fluoride in Some Natural Waters in Kenya. Journal of Hydrology, 143, 395-412. https://doi.org/10.1016/0022-1694(93)90201-J

[13] Chernet, T., Travi, Y. and Valles, V. (2002) Mechanism of Degradation of the Quality of Natural Water in the Lakes Region of the Ethiopian Rift Valley. Water Research, 12, 2819-2831. https://doi.org/10.1016/S0043-1354(01)00002-1

[14] Pontie, M., Schrotter, J.C., Lhassani, A. and Diawara, C.K. (2006) Traitement des eaux destinées à la consommation humaine. Elimination domestique et industrielle du fluor en excès. Fluor et Environnement. L'actualité chimique, 301-302, 2-7.

[15] Viswanathan, G., Jaswanth, A., Antonijevic, B., Gopalakrishnan, S., Siva ilango, S. and Aditya, G. (2009) Determining the Optimal Fluoride Concentration in Drinking Water for Fluoride Endemic Regions in South India. Science of the Total Environment, 407, 5298-5307. https://doi.org/10.1016/j.scitotenv.2009.06.028

[16] Rodier, J. (2005) L'analyse de P eau, eaux naturelles, eaux résiduaires, eaux de mer. 8ème Edition, Dunod, Paris.

[17] Mandinic, Z., Curcic, M., Antonijevic, B., Lekic, C.P. and Carevic, M. (2009) Relationship between fluoride intake in Serbian Children Living in Two Areas with Dif- 
ferent Natural Levels of Fluorides and Occurrence of Dental Fluorosis. Food and Chemical Toxicology, 47, 1080-1084. https://doi.org/10.1016/j.fct.2009.01.038

[18] Kumar, H., Boban, M. and Tiwari, M. (2009) Skeletal Fluorosis Causing High Cervical Myelopathy. Journal of Clinical Neuroscience, 16, 828-830.

https://doi.org/10.1016/j.jocn.2008.08.028

[19] Cutress, T.W. and Suckling, G.W. (1992) Differential Diagnosis of Dental Fluorosis. Journal of Dental Research, 69, 714-721. https://doi.org/10.1177/00220345900690S138

[20] Fejerskov, O., Munji, F. and Baelum, V. (1990) The Nature and Mechanisms of Dental Fluorosis in Man. Journal of Dental Research, 69, 692-700.

https://doi.org/10.1177/00220345900690S135

[21] Evans, R.W. and Stamm, J.W. (1991) An Epidemiologic Estimate of the Critical Period during Which Maxillary Central Incisors Are Most Susceptible to Fluorosis. Journal of Public Health Dentistry, 4, 251-259. https://doi.org/10.1111/j.1752-7325.1991.tb02223.x

[22] Pontie, M., Diawara, C.K., Lhassani, A., Dach, H. Rumeau, M., Buisson, H. and Schrotter, J.C. (2006) Water Defluoridation Processes A Review. Apllication: Nanofiltration (NF) for Future Large-Scale Pilot Plants. Advances in Fluorine Science, 2, 50-80. https://doi.org/10.1016/S1872-0358(06)02002-1

[23] Browne, B., Whelton, H. and O'Mullane, D. (2005) Fluoride Metabolism and Fluorosis. Journal of Dentistry, 33, 177-186. https://doi.org/10.1016/j.jdent.2004.10.003

[24] Tamer, M.N., Köroglu, B.K., Arslan, C., Akdogan, M., Köroglu, M., Cam, H. and Yildiz, M. (2007) Osteosclerosis Due to Endemic Fluorosis. Science of the Total Environment, 373, 43-38. https://doi.org/10.1016/j.scitotenv.2006.10.051

[25] Ho, Y.S. and Mckay, G. (1998) Kinetic Models for the Sorption of Dye from Aqueous Solution by Wood. Process Safety and Environmental Protection, 76, 183-191. https://doi.org/10.1205/095758298529326

[26] Ho, Y.S. and Mckay, G. (1999) Pseudo-Second Order Model for Sorption Processes. Process Biochemistry, 34, 451-465. https://doi.org/10.1016/S0032-9592(98)00112-5

[27] Langmuir, I. (1918) The Adsorption of Gases on Plane Surface of Glass, Mica and Platinum. Journal of the American Chemical Society, 40, 1361-1403.

https://doi.org/10.1021/ja02242a004

[28] Freundlich, H.M. (1906) Over the Adsorption in Solution. The Journal of Physical Chemistry A, 57, 385-470. https://doi.org/10.1515/zpch-1907-5723

[29] Almeida, C.A.P., Debacher, N.A., Downs, A.J., Cottet, L. and Mello, C.A.D. (2009) Removal of Methylene Blue from Colored Effluents by Adsorption on Montmorillonite Clay. Journal of Colloid and Interface Science, 332, 46-53. https://doi.org/10.1016/j.jcis.2008.12.012

[30] World Health Organization (2006) Guidelines for Drinking-Water Quality. World Health Organization, Geneva.

[31] Asgari, G., Roshani, B. and Ghanizadeh, G. (2012) The Investigation of Kinetic and Isotherm of Fluoride Adsorption onto Functionalize Pumice Stone. Journal of Hazardous Materials, 217-218, 123-132. https://doi.org/10.1016/j.jhazmat.2012.03.003

[32] Daifullah, A.A.M., Yakout, S.M. and Elreefy, S.A. (2007) Adsorption of Fluoride in Aqueous Solutions Using $\mathrm{KMnO}_{4}$-Modified Activated Carbon Derived from Steam Pyrolysis of Rice Straw. Journal of Hazardous Materials, 147, 633-643. https://doi.org/10.1016/j.jhazmat.2007.01.062

[33] Sivasankar, V., Rajkumar, S., Murugesh, S. and Darchen, A. (2012) Tamarind (Ta- 
marindus indica) Fruit Shell Carbon: A Calcium-Rich Promising Adsorbent for Fluoride Removal from Groundwater. Journal of Hazardous Materials, 225-226, 164-172. https://doi.org/10.1016/j.jhazmat.2012.05.015

[34] Gerente, C., Lee, V.K.C., Le Cloirec, P. and McKay, G. (2007) Application of Chitosan for the Removal of Metals from Wastewaters by Adsorption-Mechanisms and Models Review. Critical Reviews in Environmental Science and Technology, 37, 41127. https://doi.org/10.1080/10643380600729089

[35] Islam, M. and Patel, R. (2011) Thermal Activation of Basic Oxygen Furnace Slag and Evaluation of Its Fluoride Removal Efficiency. Chemical Engineering Journal, 169, 68-77. https://doi.org/10.1016/j.cej.2011.02.054 